\title{
مقدمات ثورة الفاتح من سبتمبر 1969
}

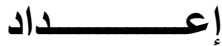

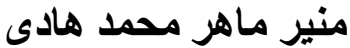 \\ طالب دكتوراه قسم التاريخ بكلية البنات جامعة عين شمس ماش
}




\section{ملخص العبحث باللغة العربية}

حصلت ليبيا على استقلالها فى ع ديسمبر 901 (م، وقد كان طريق تحقيقه لم بكن بالسهولة المعهودة.

ونحن نعلم جيدأ أن هذه البلد كان بها إقتصاد فقير يصل لدرجة العدم قبل عام 90 (م، إلا أن أهيتها تتحصر فقط فى المجال الإستراتيجى.

وأمام ذلك الأمر تكالبت الدول الأوروبية الكبرى من أجل السيطرة على ليبيا، مثل بريطانيا وفرنسا وايطاليا والولايات المتحدة، و هذا التكالب حدث قَبل وبعد استقلالها. ومنذ عام 9 ـ 9 (م قامت بريطانيا بإجراء إتفاقا مع كل من إيطاليا وفرنسا، هذا الإتفاق نص على إعطاء برقة لبريطانيا وكذلك إعطاء فزان لفرنسا لقربها من تونس إحدى بإه مستعمر اتها، وأخير أ إعطاء طر ابلس لإيطاليا.

هذا الإتفاق تم تحطيمه تماما بسبب الموقف المصرى تجاهل، فقد قامت مصر بمجهود كبير فى كافة المحافل الدولية كالأمم المتحدة وجامعة الدول العربية. بعد حصول ليبيا على الإستقلال، حرصت بريطانيا على التوصل لإتفاق مباشر مع

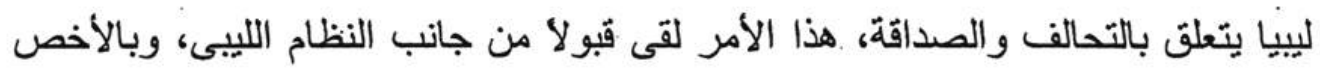

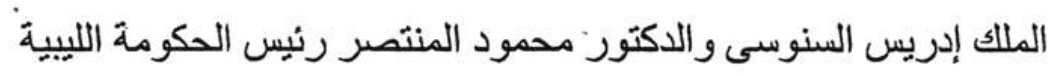
فى المقابل كانت مصر قد نجحت فى إنهاء حكم النظام الملكى فى بr يوليو 90 ام بواسطة جمال عبد الناصر قائد حركة بr يوليو ، فهذا الرجل المصرى حاول إحباط الإتفاق المشار إليه الذى تم بين ليبيا وبريطانيا. ضم هذا الإتفاق أو تلك المعاهدة سبعة مو اد وكان معها ملحق إتفاق عسكرى ومالى،

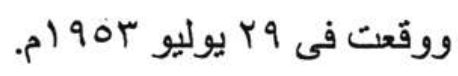
وخلال تلك الفترة التى أعقبت توقيع معاهدة التحالف الليبية البريطانية أرادث مصر

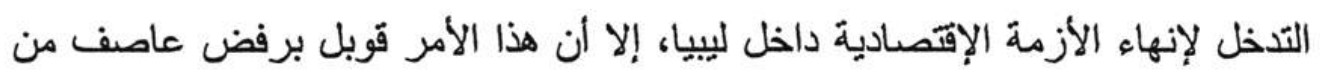
جانب كل من الملاك إدريس السنوسى وبريطانيا. 
استطاعت بريطانيا بواسطة تلك المعاهدة السيطرة على كافة المجالات مثل أوجه الحياة داخل ليبيا السياسية والإقتصادية و الإجتماعية وكذلك الثقافية. وكانت بريطانيا خلال عام عهو ام على موعد مع صراع وصدام بداته مع عبد الناصر داخل ليبيا، و افتعلت ضغوطا من أجل إنهاء تواجد مصر ذاخل ليبيا. وأصلت بريطانيا ضغوطها وصدامها مع النظام المصرى مثل مساهنها لحلف بغداد وتخليها عن نمويل مشروع السد العالى عام 907 (م، وكان نتاج تخليها عن هذا الأمر هو

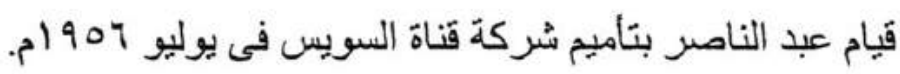
الجدير بالذكر هو تحفظ النظام الليبى تجاه تاميم شركة قناة السويس ، بسبب معاهدة

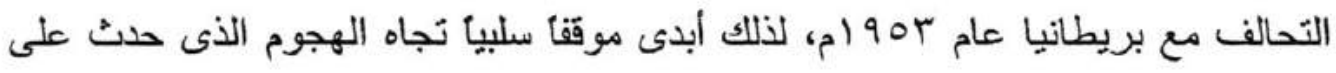

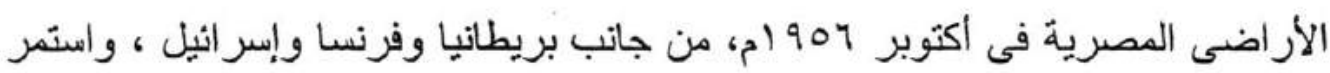

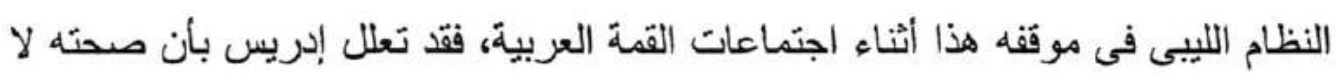
تسمح للحضور.

كانت ليبيا على مو عد خارق، فقد اكتشف البترول لأول مرة بأر اضيها عام 909 (م، وكان نتاج هذا الإكتشاف هو إنهاء الأزمة الإقتصادية التى المت بها منذ عام هـ 9 ام. استمر النظام الليبى فى ممارساته السلبية منذ نهاية عام ع 97 ام، وتفشى الفساد داخل جنبات الدولة، كما رفض وجود الثقافة المصرية داخل ليبيا. ومع تعرض مصر لنكسة يونيو 977 (م، استمر كما هو فى إتباع سياسته الخائبة، ولهذه الأسباب قاد معمر القذافى الجيُ الليبى لإنهاء حكم الأسرة السنوسية فى حركة

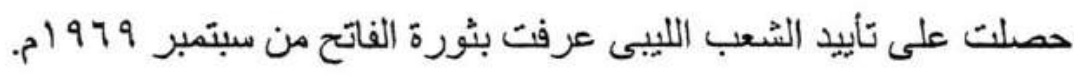




\section{The Summary in English}

Libya independent in 24 , December, 1951, this road isn't easy.

We know that this country had poor economic before 1952, but had strategic position.

So, many European countries wanted to controllable in Libya.

Example, Britain, France, Italy and United state of America, especially before and after Independence of Libya.

Since 1949, Britain worked agreement with Italy and France,

This agreement wanted give give first part called Barca to Britain, this thing happened with France, she wonted the second part in Libya, It's called Fazzan Because it's nearest Tunisia.

Finally Tripoli this a greement wanted give that part to Italy.

The agreement finished because Egyptian situation.

Egypt had many Workes in all the fields, by example in United Nation level, the Arab countries University level.

After the dependence of Libya Britain wanted agreement with Libya especially the friendship.

This subject had agreeable to Libyan regime, especially the king Idris and Mr. Hahmoud Elmontaser the president of government in Libya

In 23, July, 1952 Egypt finished the royal regime by Gamal Abdel Nasser the chef of revoluation, this Egyptian man wanted disappoint the agreement between Libya and Britain. 
This agreement consist in seven point, it's happened in 29, July, 1953, Egypt wanted to finish the economic problem in Libya, but king Idris refuse, also Britain refuse this point.

By this agreement Britain had controllable in all the field, example life in Libya "politically, economically, socially and culture".

In 1954 Britain had struggle with Nasser in Libya, and made many stress for leave Egypt in Libya.

She made many problem with the Egyptian regime, example Baghdad Union and the building of high dam.

Nasser can answered by control the Suez Canal in July, 1956.

The Libyan regime rufuse this point because friendship agreement with Britain in 1953 and he made dirty situation especially the attack which happened in October, 1956 in Egyptian Land by Britain and France and Israil.

Economic problem in Libya had finished in 1956 because the petroleum.

In the last Libyan regime made dirty work since the end of 1964.

He refuse the Egyptian Culture in Libya and made dirty situation in the sixth day war in June, 1967.

For this reason Al-Qathafi can led the army in revoluation which called the first of September, 1969. 


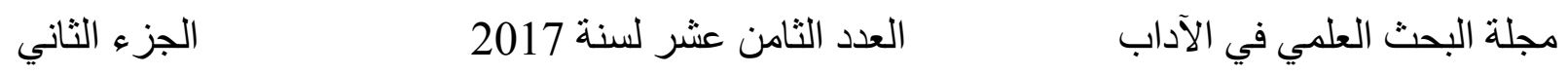

استند النظام الليبى خلال عهد إدريس السنوسى على ثلاث قوى أساسية وهما القبائل، والزوايا السنوسية،

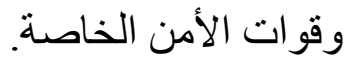

القوة الأولى أخذت تتهاوى بعد اكتشاف البترول أواخر عام 1959م، حيث أغرى أبناء العشائر ونقلهم من الحياة البدائية إلى حياة غلب عليها الطباع الحضرية، وخلال ذلك الوقت حدث تغيير فى نظام الملكية داخل ليبيا، وكان من المنتظر ازدياد قوة النظام القبلى عقب حصولها على الإستقلال مطلع عام

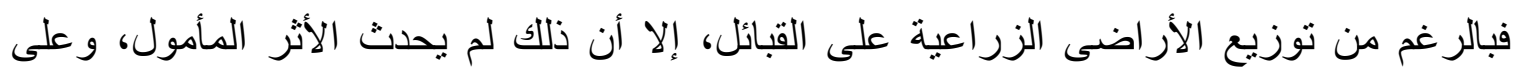
العكس فقد ساهم ذللك التوزيع فى انحصار الملكيات الكبيرة فى أيدى القليل من اللبييين، وكان من المنتظر قياما لدولة الليبية بتدعيم الزوايا التى استردتها بعد الاستقلال، فقد بدأت الحكومة الليبية فى تخصيص احد بنود الميزانية لمساعدة تللك الزوايا، ووضعت تحت إثر اف ناظر الخاصة الملكية، والذى كان أداه لحكم إدريس السنوسى ، وكان يعين بتوجيهات من بريطانيا بمقتضى معاهدة التحالف عام 1953م (1). وحاول إدريس السنوسى إيجاد قوة مادية تكون درعاً واقياً له ولنظامه الحاكم، لعدم وجود جيش بالثكل المطلوب لوقوعه فريسة للهيمنة البريطانية بمقتىى معاهدة التحالف، لذا قرر إدريس تشكيل قوات آمن خاصة فى فبر اير 1963م، و عكف على زيادة ميزانية تلك القوات، حيث قدرت بأربعة عشر مليون جنيه ليبي، فى المقابل عمد لتقليص ميز انية الجيش، التى قدرت بتسعة ملايين جنيه ليبي فقط عام 1967م، و واستمر فى مشكله خلال عامى 1968م، 1969م، وسرعان ما تسبب ذلك الإجراء فى حدوث إستياء الرأى العام

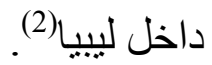

كان المجتمع الليبى قد شهذ ظهور طبقتان جديدتان عقب استثمار ثروة البترول الأولى وهى الطبقة الر اسمالية عام 1959م والثانية هى الطبقة العاملة، إتجىت الأولى إلى تنفيذ المشرو عات التجارية الإستهلاكية كتشييد المبانى الفاخرة ، واضطر النازحون للمدن إلى استثمار ها بأسعار مرتفعة الأمر الذى ساعد على تسرب الأجور العالية الخاصة بالأيدى العاملة إلى جيوب هذه القلة من المحتكرين، فهوُلاء هم الذين جنوا

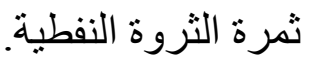
وكان بإمكان الرأسمالية الناشئة الإستثمار فى الزر اعة و المر اعى على الأقل، إلا أنهم لم يتجهو الذلك بسبب الضغوط البريطانية الو اقعة عليهم، هذه الضغوط جعلت ليبيا تتجه لإستير اد الحوم من بريطانيا، بعد أن كانت لعهد قريب مصدر اً هاماً للحيو انات(3). 


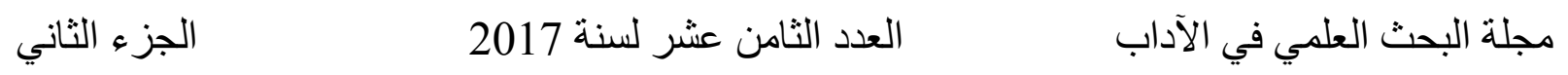

وحول السياق ذاته كلفت الأمم المتحدة بتشكيل لجنة تعهدت بدراسة أحوال لبييان وتمكنت إبان تشكيلها من إيضاح أنواع المعونة الفنية التى طالبت بها ليبيا، وبالرغم من ذلك فضلت الحكومة الليبية بقيادة محمود المنتصر المساعدات التى جاءت نتاج لمعاهدة التحالف المبرمة مع بريطانيا عام 1953م ، وقلصت حاجتها للمعونات الآتية من مصر، واستمرت بذلك بريطانيا فى احتلال مركز الصدارة تجاه إقامة

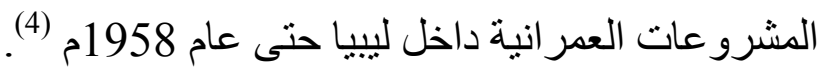
ومع إتساع نطاق الأعمال داخل ليييا قررت الحكومة الليبية برئاسة عبد المجيد كعبار اللجوء للخبرات البريطانية لإدارة البلاد وتجاهلت الخبرة المصرية، الأمر الذى ساهم فى إنتقال روح الفساد إلى لى لئل المواطنين الليبيين الذين انغسوا فى سلك الإدارة ، فهؤلاء كانو ا يعملون بتوجيهات غير مباثرة من جانب بريطانيا(5).

حاول كعبار تنفيذ بعض الإصلاحات، غلا أنها كانت فى جوهر ها أنثياء شكلية ، مثل إعادة توزيع الدوائر الانتخابية، وإقرار مبدأ التصويت السرى خارج الددن الليبية ، و إدخال وجوه موالية لأفكار ها داخل البرلمان ، إلا أن هذه العناصر لم تكن إصلاحية، فقد فثلت فى معالجة إحدى قضايا الاختلاس المتعلقة بطريق فزان، والذى أقيم من أجل إغر اء شركات البترول على التهن التنقبب داخل ليبيا(6). وكانت حكومة كعبار قد قامت بإرساء عطاء إنشاء الطريق على شركة ساسكو التى يمتلكها عبد الله عابد السنوسى، وكان يتعامل مع الثركات البريطانية ، وبررت حكومة كعبار قيامها بإرساء العطاء عليه مدعيه بأن شركته قد تقدمت بأدنى عطاء، حيث تعهدت بيناء الطريق مقابل مليون وتسعمائة ألف جنيه ليبي ، إلا أن الحقيقة اتضحت بواسطة صاحب العطاء نفسه، حيث ذكر أن العطاء كان يتعلق بجزء من الطريق، و أكد أنه طالب بأربعة ملايين جنيه أخرى من حكومة كعبار (7). اعتبرت هذه القضية نموذجاً للفساد الذى انتشر فى أجهزة الدولة الليبية، لذلك قرر إدريس مواجهة هذا الفساد خوفاً من أن يزج بإسمه فى أنون تلك القضية الثائكة، وبمرور الوقت إزداد موقف حكومة كعبار حرجاً ، وتو الت أخطاؤها فى معالجة القضية، ولم يجد كعبار مفراً الإنهاء ذللك الأمر سوى التقام بالإستقالة، ومن هنا ضاع الموضوع الأصلى للقضية داخل خضم أزمة وز ارية(8). بدأ إدريس السنوسى يستشعر القلق خلال الحقبة الأخيرة من عهده تجاه جيل المثققين من الليبين لتحمسهم لأفكار عبد الناصر التحررية ضد الوجود البريطانى ، لذللك جاء بحكومة محمد عثمان الصيد أواخر عام 1960م، فقد شهد عهد هذه الحكومة محاكمة كبرى لمثقفى ليبيا، بلغ عددهم 159 شخصاً معظمهم من 


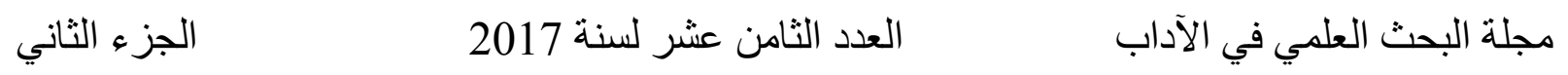

الثبان الجامعيين فى ديسمبر 1961م، وكالعادة حاول إدريس تهيئة الر أى الثائر من تصرفات حكومة محمد عثمان، فقرر إقالتهاوتعيين دكتور محيى الدين فكينى خلفاً له على رأس الحكومة فى مارس دئ 1963م (9). حاول فكينى إجر اء إصلاحات هامة بارجاء الدولة، وحارب الفساد الذى تغلغل بها، ولعل إدريس السنوسى أر اد بذلك التغيير وضع السياسة الإصلاحية فى موضع التجربة العملية، ومن ثم إرضاء الر أى العام الشعبى الذى ضاق كثير اً من مو الاته لبريطانيا، وبالر غم من كل هذا فقد فثل إدريس فى تحمل حكومة فكينى

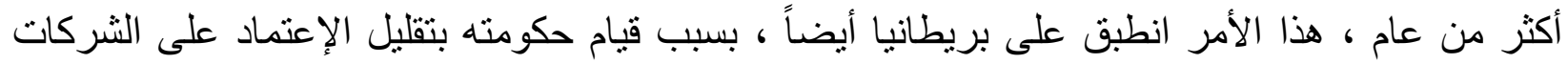
التابعة لبريطانيا ، ومن ثم محاولتها لإخضاع إقتصاد البلاد. عجز فكينى عن مواجهة مسألة قوات الآمن الخاصة التى شكلها إدريس بالتنسيق مع بريطانيا،

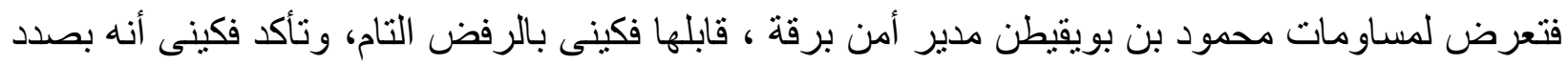
مؤ امرة منظمة، فطلب من إدريس سر عة التنخل و إقالة بويقيطن، إلا أنه فوجئ برفض طلبه. وبمرور الوقت شعر الرأى العام الثعبى داخل ليييا بالإستياء والحزن، بعد أن رأى تجاهل إدريس لحضور مؤتمر القمة العربية الأول بالقاهرة عام 1964م، وسرعان ما قامت المظاهرات المناهضة لذلك

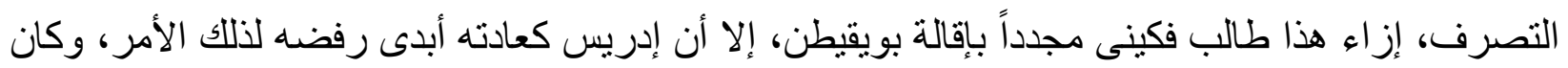
المشهد الحتمى لحكومة فكينى الإستقالة(10).

استدعى إدريس محمود المنتصر لكى يشكل حكومة جديدة خلفاً لمحيى الدين فكينى فى يناير 1964م، ولم يمض وقت طويل حتى كان عليه أن يو اجه أول مشكلة كبيرة، فقد ألقى الرئيس الراحل جمال

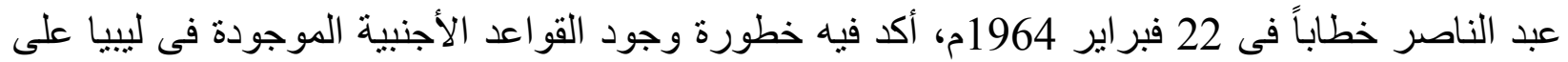
الأمة العربية كلها، وسرعان ما أدى ذلك إلى تأجيج غضب الثُب الليبى على حكومة المنتصر. حاول المنتصر تهدئة غضب الثعب، حيث كلف حسين مازق وزير خارجيته ببدء مفاوضات الجلاء مع بريطانيا والولايات المتحدة، وأكد المنتصر أن بريطانيا قد أبدت قبولها لمبدأ تصفية قو اعدها الموجودة داخل ليبيا، مشيراً إلى أن هذا قد يتطلب بعض الوقت حتى ينفذ بالثكل اللائق، وخلال هذه الفترة نجح المنتصر فى التخلص من المعارضة التى أثنارت أمر القواعد البريطانية وذلك بحل مجلس النواب، وقرر إجر اء الإنتخابات ، هذه الإجر اءات أسعدت إدريس ، الذى لم يستطع إخفاء مشاعره الطيبة تجاه بريطانيا، عندما اقترح التنازل عن عرشه عقب مطالبة مجلس النواب ببحث أمر القواعد العسكرية البريطانية ، هذاء 


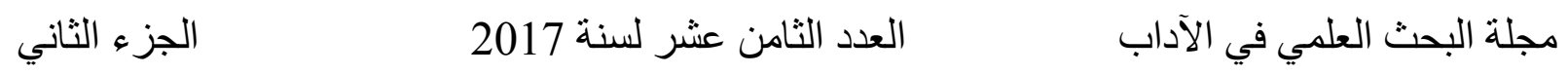

الأمر انطبق أيضاً على محمود المنتصر فقد انتقل هو الآخر إلى طبرق لممارسة الضغط على المعارضة فى ظل تو اجد الأسطول البريطانى بهاب(11).

وبعد إبرام صفقة الأسلحة البريطانية الكبرى مع حكومة المنتظر عام 1968م ، و المعروفة بصفقة

القرن فقد إزدادت مشاعر الإستياء من نظام إدريس السنوسى، وأدرك الجيل الجديد حتمية التغيير الجذرى داخل الدولة الليبية، وبالر غم من ذللك حاول إدريس استعادة ما تبقى من نظامه ، فبعد إزدياد السخط الثعبى لئى بسبب موقف حكومة محمود المنتصر وسياستها غير التوافقية مع سائر اللبييين، قرر إدريس إقالتها فى بـ مارس 1965م، عقب تدهور صحة المنتصر (12). وجاء حسين مازق خلفاً له فى 21 مارس 1965م، واستمر فى تنفيذ الخطة الخمسية للتنمية الاقتصادية (1963 - 1968م) ، و أبدى كراهيته لبعض الرجال المحيطين بإدريس السنوسى مثل عبد الله عابد السنوسى، وأمام ذللك أرسل مازق إلى إدريس تقريراً يبين فيه تجاوزاته المالية، وبعد هزيمة الدول

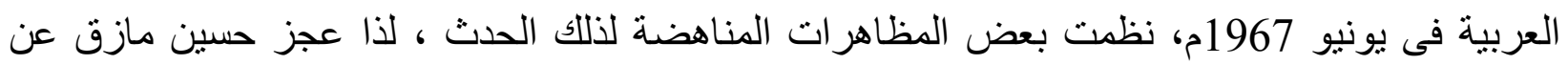
مو اجهة الغضب الثعبى، وبالتالى سارع بالتقدم بالإستقالة فى 29 يونيو 1967م لنطئ (13). جاء عبد القادر البدرى خلفاً لحسين مازق فى أول يوليو 1967م، وبدأ عمله بالصدام مع عمال الثحن، الذين أرادوا الإمتتاع عن تصدير البترول إلى بريطانيا لدعمها غير المباثر لإسر ائيل فى عدو انها

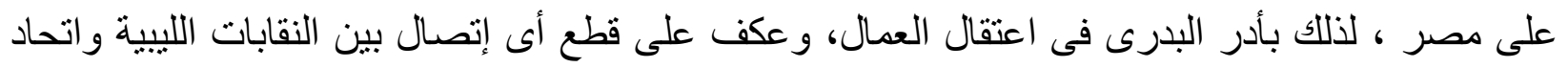
نقابات العمال العرب، وفى المقابل واصل إدريس إمتتاعه عن المشاركة فى مؤتمر القمة الطارئ الذى عقد بالخرطوم منتصف أغسطس 1967م ، إلا أنه أر اد تحسين صورته أمام شعبه، فأعلن عن مساهمته فى الدعم المالى للدول المتأثرة بالعدوان الاسر ائيلى، هذا الإجر اء لم يسعف إدريس وحكومته على تحسين صورتهما المهتزة وسر عان ما ازداد سخط الر أى العام أكثر من ذى قبل، فقرر إدريس السنوسى إقالة حكومة عبد القادر البدرى فى أكتوبر 1967م (14) مشئ.

تولى عبد الحميد البكوش مسئولية إنقاذ ما تبقى إنقاذه من شعبية إدريس السنوسى التى تضاءلت، وبالر غم من ذللك استمرت حكومته فى سياستها القائمة على التقصير و التجاهل تجاه معالجة القضايا العربية، وتعامل مع هذا المر من منظور إقتصادى ، فهو الذى شغل من قبل منصب مستشاراً لإحدى الثركات البريطانية، كما تفاوض على صفقة الأسلحة المشار إليها المعروفة بصفقة القرن، وافتعل أزمات عديدة مع مع لإن بعض الحكومات غير المحبة لبريطانيا ولتو اجدها داخل ليبيا(15). 
هكذا إزدادت معدلات الفساد بشكل مكثف داخل ليبيا خلال الفترة من عام 1964م وحتى عام 1969م، وصاحب هذا الأمر عدم الإستقرار من الناحية السياسية، وتهاوت شعبية إدريس لإستمراره فى دئ سياسته المو الية لبريطانيا ، وتجاهله للاول العربية و على رأسهم مصر. هناك مظهر آخر يؤكد عدم وجود الإستقرار السياسى فى ليبيا وهو تعاقب الحكومات تلو الأخرى خلال مدة ليست بالكبيرة، فقد حاولو ا موالاة إدريس السنوسى وبريطانيا باستثناء حكومة الدكتور محيى الدين

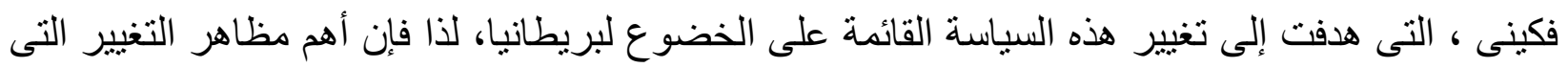
ترتبت على قيام ثورة الفاتح من سبتمبر 1969م كانت تتعلق فى جو هر ها بتوجهات السياسة الخارجية لليبيا.

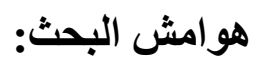

وثائق الخارجية المصرية، محفظة (1) ، ملف (8) ، تحت رقم 1/86/746، ج (2) ، تقارير صحفية للسفارة المصرية فى ليبيا، "تقرير السفير المصرى بلييا للخارجية المصرية بشأن أحوال لييا

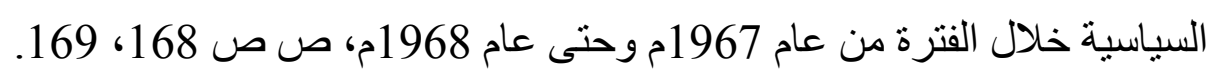

مضابط مجلس النواب الليبى، الفصل التشريعى التاسع عشر ، جلسة (39) ، السبت 26 أبريل 1969م ، "استجواب سالم بن الكعبى المقدم للحكومة بشأن تقليص إدريس لموازنة الجيش المعتمدة لعام 1969- 1970م، ص 2568.

(3) Lemonde, French Journal, Issue No. 2501, Sat., 13, Dec., 1969, p. 2 www.Google.com.

أحد الفنيش، المجتمع الليبى ومشكلاته ، طر ابلس ، 1969م، ص 141.

وثائق الخارجية المصرية، محفظة (4)، ملف (68)، رقم 3/7/242، ج (2)، التقرير النصف سنوى

خلال الفترة من يناير وحتى يونيو 1960م ، إعداد مصطفى عبد القوى ، ص 18.

صلاح العقاد ، ليبيا المعاصرة، معهد الدراسات والبحوث العربية ، القاهرة ، 1970م ، ص ص

(7) U.N., Year book, 1952, 1954, 1961, New york, 1962, pp. 14, 28. 


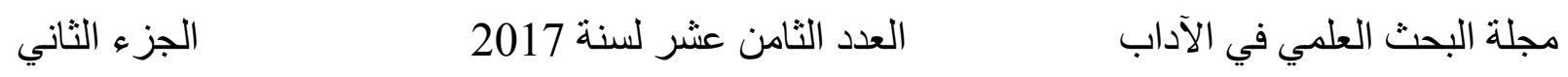

مضابط مجلس النواب الليبى، الفصل التشريعى العاثشر ، جلسة (68)، جلسة غير اعتيادية، الخميس

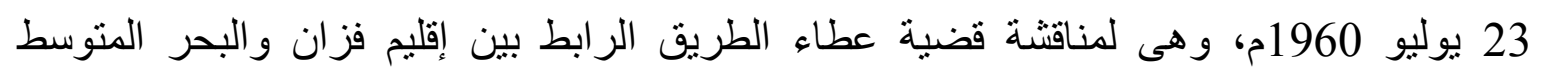

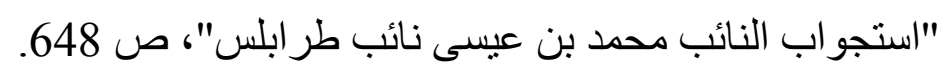

وثائق الخارجية المصرية، محفظة (4) ، ملف (68)، تحت رقم 3/7/242، ج (2) ، التقرير السياسى

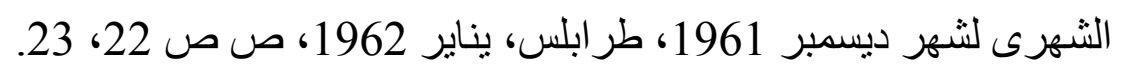
(10) الطاهر أحمد الزاوى، أعلام ليبيا، دار المنار الإسلامى، لبنان ، 2004م، ص ص 68، 69، الأهر ام،

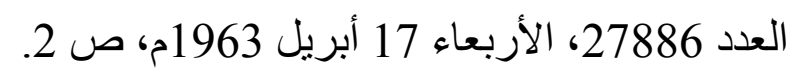

(11) جامعة الدول العربية، المحاضر الختامية لجلسات دور الإجتماع التاسع والثناثين الاستثنائى على مستوى القمة العربية الأولى بالقاهرة فى يناير 1964، ص ص 28، 29، 29، محمد يوسف المقريف،

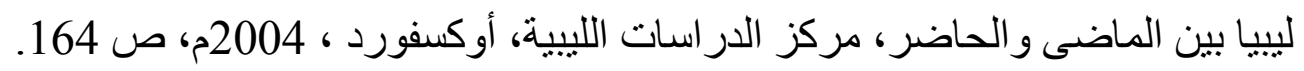
(12) مصطفى بن حليم، صفحات مطوية من تاريخ ليبيا السياسى، "وثائق وصور"، مطبعة الأهرام، القاهرة، 1992م، ص ص صن 11 31، 32.

(13) السيد عوض عثمان، العلاقات الليبية الأمريكية (1940- 1992)، ط (1) ، مركز الحضارات ، القاهرة، 1994م، ص 68.

(14) سالم الكبتى، ليبيا مسيرة الإستقلال ، "وثائق محلية ودولية"، ج (3) ، ط (1) ، الدار العربية للعلوم ، القاهرة، 2012م، ص ص الم 124. (15) سامى حكيم ، هذه ليبيا، مكتبة الأنجلو ، القاهرة، 1970م، ص 216. 